University of New Hampshire

University of New Hampshire Scholars' Repository

8-2009

\title{
Ice storm effects on the canopy structure of a northern hardwood forest after 8 years
}

Brian C. Weeks

Steven P. Hamburg

Brown University

Matthew A. Vadeboncoeur

Brown University, matt.vad@unh.edu

Follow this and additional works at: https://scholars.unh.edu/ersc

Part of the Ecology and Evolutionary Biology Commons, and the Forest Sciences Commons

\section{Recommended Citation}

Weeks BC, Hamburg SP, Vadeboncoeur MA. 2009. Ice storm effects on the canopy structure of a northern hardwood forest after eight years. Canadian Journal of Forest Research 39:1475-1483

This Article is brought to you for free and open access by the Institute for the Study of Earth, Oceans, and Space (EOS) at University of New Hampshire Scholars' Repository. It has been accepted for inclusion in Earth Systems Research Center by an authorized administrator of University of New Hampshire Scholars' Repository. For more information, please contact Scholarly.Communication@unh.edu. 


\title{
Ice storm effects on the canopy structure of a northern hardwood forest after eight years
}

\author{
Brian C. Weeks, Steven P. Hamburg, and Matthew A. Vadeboncoeur
}

Center for Environmental Studies

Brown University

135 Angell Street, Box 1943

Providence, RI 02912

\begin{abstract}
Ice storms can cause severe damage to forest canopies, resulting in differential mortality among tree species and size classes and leading to long-lasting changes in the vertical structure and composition of the forest. An intense ice storm in 1998 damaged large areas of the northern hardwood forest, including much of the Hubbard Brook Experimental Forest, New Hampshire (USA). Following up on detailed post-storm assessments, we measured changes in the vertical structure of the forest canopy eight years post-storm. We focused on how the presence of disease-induced advance regeneration of American beech (Fagus grandifolia Ehrh.) has affected canopy structure in the recovering forest. We measured foliage-height profiles using a point-quadrat approach and a pole-mounted leaf area index (LAI) sensor. While the total LAls of damaged and undamaged areas were similar, areas damaged in 1998 showed an increased proportion of total leaf area between 6 and $10 \mathrm{~m}$ above the ground. The foliage at this height is largely (54\%) beech. To the extent that this heavily beech-dominated understory layer suppresses regeneration of other species, these findings suggest that rare disturbances of mature northern hardwood forests affected by beech bark disease will increase the importance of damage-prone and economically marginal beech.
\end{abstract}

This reformatted accepted manuscript is made available by the author, in accordance with the author rights policy of NRC Research Press.

The formatted final version is available from the publisher at http://dx.doi.org/10.1139/X09-076

This document should be cited as:

Weeks B.C., Hamburg S.P., Vadeboncoeur, M.A. 2009. Ice storm effects on the canopy structure of a northern hardwood forest after eight years. Canadian Journal of Forest Research 39:1475-1483. 


\section{INTRODUCTION}

Severe ice storms are an infrequent but intense natural disturbance in many temperate forests, including those in the northeastern United States. During severe ice storms, ice accretion may temporarily increase canopy mass by $100 \%$, which, coupled with strong winds, can lead to the breaking of branches and bole snapping in mature trees, as well as the bending of smaller trees (Melancon and Lechowicz 1987). Previous research has found tree architecture to be important in explaining the differential impact of ice build-up among species (Lemon 1961). However, size, mechanical properties, age, and health (Lemon 1961; Boerner et al. 1988; Seischab et al. 1993) have also all been linked to differential species susceptibility. In addition to tree-related variables, soil conditions (including slope, texture, and depth) have been found to affect damage patterns (Whitney and Johnson 1984; Boerner et al. 1988; Warrilow and Mou 1999).

Despite differences among species in their resistance to damage, in forests affected regularly by ice storms there are no shifts in species composition if all canopy species are well represented in the understory (Whitney and Johnson 1984: Warrilow and Mou 1999). Yet, in forests undergoing successional species shifts, changes in species composition may be accelerated (Lemon 1961).

In 1998, the most severe ice storm in the historical record hit the northeastern United States and southeastern Canada. In the United States, $7 \times 10^{4} \mathrm{~km}^{2}$ were impacted, with as much as $11 \mathrm{~cm}$ of precipitation in 100 hours (Dobbs 1999; DeGaetano 2000). Hooper et al. (2001) reported that up to $10 \%$ of forest biomass was lost in parts of Québec; in New Hampshire, 427,000 ha of forest were damaged (Bofinger 2001; Irland 1998). Rhoads et al. (2002) estimated that some parts of the Hubbard Brook Experimental Forest (HBEF), showed leaf area index (LAI) reductions of about one-third during the growing season following the storm. The damage in HBEF was limited to areas of higher elevation, with little to no damage below $560 \mathrm{~m}$ in Watershed 1, and $624 \mathrm{~m}$ in Watershed 6 (Rhoads et al. 2002). Three growing seasons post-storm, total LAI had returned to estimated pre-storm levels (Rhoads et al., 2002), despite an obvious shift in foliage-height profiles.

An altered canopy structure can influence both biotic and abiotic forest processes. Canopy structure strongly influences bird foraging patterns and bird community structure (e.g., MacArthur and MacArthur 1961; Holmes and Sherry 2001; Faccio 2003). Ice storm-caused gaps have been reported to lead to increases in lateral growth of surrounding trees, though the response may be delayed (Oliver and Larson 1996). Ice storm damage has also been shown to increase rates of root and canopy growth up to two growing seasons post-storm (Rhoads et al. 2002; Battles and Fahey 2000). The vertical distribution of leaves in the forest canopy influences its photosynthetic and transpiration rates as well as its nutrient content (Aber 1979a; Forester et al. 2000). Because of these effects, it is important to understand the pattern of canopy recovery following the ice storm, which can be expected to exceed the time it takes total LAI to recover.

The degree of canopy damage resulting from the1998 ice storm varied greatly among the dominant tree species at HBEF, with American beech (Fagus grandifolia Ehrh.) most heavily impacted, in part because they were substantially weakened by beech bark disease (Rhoads et al. 2002). The stress of this disease, (an infection by a Nectria fungus, spread by the introduced insect vector Cryptococcus

fagisuga), leads to infested trees initiating large numbers of root sprouts (Houston 1975; Hane 2003). The presence of this advance regeneration in the understory may explain a dramatic decrease in sugar maple (Acer saccharum Marsh.) regeneration (Hane 2003; Hane et al. 2003).

In this study, we revisited the plots established by Rhoads et al. (2002) to investigate the recovery of the forest canopy of the HBEF 
following the 1998 ice storm. We re-measured total LAl three times: in 2001, 2005 and 2006, and characterized the canopy-height profiles of damaged and undamaged areas in 2005 . These additional data allow us to test the following hypotheses:

1. Canopy-height profiles of ice-damaged areas remain significantly different than canopyheight profiles in undamaged areas eight years post-storm.

2. The relative importance of beech leaf area has increased in damaged areas.

3. In areas that did not have advance beech regeneration when damaged, LAI has been slower to recover than in areas with abundant beech regeneration.

4. The density of intermediate-sized beech trees has increased more in damaged areas than undamaged areas.

Together, if confirmed, these hypotheses would support the speculation that the ice storm, which damaged diseased beech disproportionately, has led to an increase in the dominance of sub-canopy beech at HBEF (Rhoads et al. 2002). The extent to which this trend will ultimately lead to a shift towards beech in the overall species composition of the forest will require further monitoring.

\section{METHODS}

\section{Study site}

The HBEF, located in Woodstock, $\mathrm{NH}$ $\left(43^{\circ} 56^{\prime} \mathrm{N}, 71^{\circ} 45^{\prime} \mathrm{W}\right)$ is a northern hardwood forest, dominated by American beech, sugar maple, and yellow birch (Betula alleghaniensis Britton). At higher elevations and on rock outcrops, red spruce (Picea rubens Sarg.), white birch (Betula papyrifa Marsh.), and balsam fir (Abies balsamea L.) are dominant (Bormann et al. 1970; Schwarz et al. 2001). The climate is cool and humid; mean January temperature is $8.3^{\circ} \mathrm{C}$ mean July temperature is $18.7^{\circ} \mathrm{C}$, and annual precipitation averages $137 \mathrm{~cm}$ (Bailey et al. 2003). Soils are mostly well-drained spodosols on unsorted basal till, with an average depth of $2 \mathrm{~m}$ from surface to bedrock (Bormann et al. 1970).

All measurements in this study were made on watersheds 1 and 6 (W1, W6), in $15 \times 15$ m plots studied by Rhoads et al. (2002). Both watersheds were cutover in the 1880 s and again in the 1910s with some salvage logging following the 1938 hurricane. Total live biomass on W6 is approximately $220 \mathrm{Mg} / \mathrm{ha}$, and has been stable since the 1980s (Fahey et al. 2005). W6 serves as the biogeochemical reference watershed, and has not been manipulated since the establishment of the experimental forest in 1955 . W6 covers 13.2 ha with an average slope of $16^{\circ}$ and a southeastern aspect and elevation ranging from $550-790 \mathrm{~m}$. W1 covers 11.8 ha with southeastern aspect, an average slope of $19^{\circ}$, and an elevation ranging from 490-750 m. In October 1999, W1 was treated with $\mathrm{CaSiO}_{3}$ pellets at a rate of $1.6 \mathrm{Mg}$ $\mathrm{Ca} / \mathrm{ha}$ as part of a cation leaching experiment (Peters et al. 2004). There is no evidence that this addition has impacted total LAI or canopy structure in W1. In 2002 W6 had a basal area of $28.4 \mathrm{~m}^{2} /$ ha and W1 $29.0 \mathrm{~m}^{2} / \mathrm{ha}$.

The only major ice storm recorded at HBEF in the second half of the $20^{\text {th }}$ century occurred between January 5 and 11, 1998; over the course of the storm temperatures ranged from 1 to $1^{\circ} \mathrm{C}$ and over $75 \mathrm{~mm}$ of melted precipitation fell in the Hubbard Brook valley (Rhoads et al. 2002). Visual observations indicated that ice accumulated above $560 \mathrm{~m}$ on W1 and above $624 \mathrm{~m}$ on W6. All LAI data are pooled data by the damage classes assigned to each plot by Rhoads et al. (2002) shortly poststorm.

\section{Canopy profile measurements}

To measure the heights of individual leaves we used a camera with a $35 \mathrm{~mm}$ telephoto lens that served as a range-finder. A grid of 15 points was etched into the camera's mirror, and used as a set of sampling points for leaf height measurements. We adjusted the focus for the 
leaf at each grid point, and recorded the distance corresponding to each focal setting. The camera was kept steady and vertical using a tripod; measurements were taken at 7 random locations along a transect extending from the northeast corner to the southwest corner of each $15 \mathrm{~m} \times 15 \mathrm{~m}$ plot used by Rhoads et al. (2002); this gave a total of 105 measurements per plot. Leaf-height measurements were taken $2 \mathrm{~m}$ away from the transect, alternating between $2 \mathrm{~m}$ northwest and $2 \mathrm{~m}$ southeast. The height of the lowest leaf intersecting each point on the camera lens was measured and recorded according to the methods set by MacArthur and Horn (1969), as revised by Aber (1979a). If none of the 15 measurement points was at least $10 \mathrm{~m}$ above ground or in open sky, the data for that point were discarded and a new set of measurements was taken $2 \mathrm{~m}$ further away from the transect in the same direction. We calculated the proportion of total LAI within each $3 \mathrm{~m}$ stratum at the plot scale using the equation:

$$
\mathrm{y}=\ln \left(\mathrm{N}_{\mathrm{fi}} / \mathrm{N}_{\mathrm{f} 2}\right)
$$

where $y$ is the proportion of total LAl between heights $f_{1}$ and $f_{2}$ and $N_{f i}$ is the number of points above $\mathrm{f}_{1}$ and $\mathrm{N}_{\mathrm{f} 2}$ is the number of points above f2 (Aber 1979a). We report results pooled by damage class, with $95 \%$ confidence intervals. Differences between damage classes in percent of total LAI in a given stratum were analyzed using unpaired $t$-tests.

To compare the profile data with total LAI data, we used a plant canopy analyzer (LAI-2000, LiCor Inc., Lincoln, Nebraska) to record LAI at $1 \mathrm{~m}$ intervals up to $10 \mathrm{~m}$ in four undamaged plots as well as seven plots with varying degrees of damage using the points of measure established by Rhoads et al. (2002) in W6. We placed the analyzer on a $10 \mathrm{~m}$ telescoping pole, moving it up at $1 \mathrm{~m}$ intervals. Since it was difficult to keep the sensor steady we calculated LAl above the sensor at each height using all five rings (0-68 ${ }^{\circ}$ from the zenith). We report mean cumulative LAI below each height step up to $9 \mathrm{~m}$.

\section{Total LAI measurements}

Total LAI measurements were taken using the LAI-2000 plant canopy analyzer (LAl-2000, LiCor Inc., Lincoln, Nebraska), at 1 and 2 meters height, following Rhoads et al. (2002). In each of the thirty-two permanently marked $15 \mathrm{~m} x$ $15 \mathrm{~m}$ square plots, measurements were taken at each of the ten random points marked by Rhoads et al. (2002). Measurements for 1998, 1999, and 2000 were reported by Rhoads et al. (2002). We took total LAI measurements in 2001 and 2005 on all plots, and in 2006 on W6 only. All measurements made with the LAI2000 were taken in July and August under clear skies during 30-40 minute periods immediately after sunset or immediately before sunrise to take advantage of diffuse lighting conditions. Our procedure for data collection was identical to the procedure developed by Rhoads et al. $(2002,2004)$ which was found to produce results comparable to litterfall collection at the watershed level, though with higher precision at the plot level (Rhoads et al. 2004). This method has also been verified against litterfall collection in other forests (Coops et al. 2004). The outer two rings of the sensor were eliminated for computation of LAI at 1 and $2 \mathrm{~m}$, so that the sensor view was from $0-43^{\circ}$ from the zenith as done by Rhoads et al. (2004).

The data were pooled by damage class; plots below $560 \mathrm{~m}$ on W1 and $624 \mathrm{~m}$ on W6 (hereafter referred to as "low elevation" plots) were used as undamaged references $(n=10)$. For the examination of long-term trends, the damaged plots were further subdivided into "mid elevation" ( $<10 \mathrm{~m}, n=14)$ and "high elevation" (> $710 \mathrm{~m}, n=8$ ) bands, following Rhoads et al. (2002). As a metric of recovery at the scale of individual plots, we compare the LAI measurement taken at $2 \mathrm{~m}$ in 1998 (first growing season post-storm) to the mean of the $2 \mathrm{~m}$ measurements taken in 2001, 2005, and 2006 (years 4, 8, and 9 growing seasons poststorm). The data for 2001, 2005 and 2006 were combined to reduce noise created by interannual variability in the "recovered" postdisturbance canopy, but data from 1998 were 
not combined with any other years because LAI shows significant recovery by 1999 . Differences in mean total LAI between years and elevation classes were compared using unpaired $t$-tests. Linear regression was used to examine the relationship between total LAI and elevation; each plot was examined for 1998 and the mean "recovered" period data using linear regression. A similar regression analysis was performed using the proportion of each plot's basal area in northern hardwood species (beech, yellow birch, and sugar maple) in 1997, (Siccama unpublished data, www.hubbardbrook.org).

\section{Canopy species composition data}

In order to identify the trees that accounted for the leaves in each height stratum, we developed a branch height-DBH relationship using all 110 LAl sampling points in W6 (4 undamaged and 7 damaged plots, each with 10 sampling points). Moving the $10 \mathrm{~m}$ telescoping pole up through the canopy at one-meter intervals, we determined the $\mathrm{DBH}$ and species of the tree to which each leaf within $50 \mathrm{~cm}$ of the pole was attached. The DBH data from each 1-m branch height class was analyzed using an unpaired $t$-test to compare the means between damaged and undamaged plots.

We used the W6 vegetation inventory from 1997 and 2002 (Siccama unpublished data, www.hubbardbrook.org) to determine how the stem density of beech trees in each of seven DBH size classes $(2.0-4.9 \mathrm{~cm} ; 5.0-9.9 \mathrm{~cm} ; 10.0$ - $14.9 \mathrm{~cm} ; 15.0$ - $19.9 \mathrm{~cm} ; 20.0$ - $29.9 \mathrm{~cm} ; 30.0$ $39.9 \mathrm{~cm}$; and $\geq 40.0 \mathrm{~cm}$ ) was altered by the 1998 ice storm. Considering only "healthy" (alive without obvious crown decline) trees, we compared the change in stem density in the undamaged plots (elevations $550-624 \mathrm{~m} ; \mathrm{n}=$ $47)$ to the change in the damaged plots (elevations $624-780 \mathrm{~m} ; \mathrm{n}=142$ ) using an unpaired two-tailed $t$-test.

\section{Results}

\section{Vertical profile of canopy LAI}

Based on measurements made using the camera, the proportion of total canopy leaf area in the $6.0-9.9 \mathrm{~m}$ height stratum was significantly greater in the damaged plots $(54 \%$ $\pm 6 \%$ ) than in the undamaged plots $(35 \% \pm 6 \%$;

Fig 1 ). This corresponds to roughly $50 \%$ more leaf area ( $15 \%$ more of the total canopy) located at this height in the damaged plots $(\mathrm{p}<$ 0.01 by both methods; Fig. 1; Fig. 2). The increase in the proportion of total LAl at 6.0 $9.9 \mathrm{~m}$ in the damaged plots appears to offset a large decline in the proportion of LAI above 14 $\mathrm{m}$ in damaged plots $(10 \% \pm 5 \%)$ relative to undamaged plots $(31 \% \pm 11 \%)$. However, total cumulative LAl to a height of $16 \mathrm{~m}$ was similar between damaged and undamaged plots (Fig 2). If we assume that the canopy profiles were initially similar prior to the ice storm, it is clear that recovery of LAI has occurred largely in the 6.0-9.9 m height stratum. For reference, both damaged and undamaged forests showed a higher proportion of total LAl below $6 \mathrm{~m}$ and a smaller proportion above $14 \mathrm{~m}$ than the nearby old-growth forest examined by Aber (1979) using the same method (Fig 1).

\section{Post-storm trends in total LAI}

Total LAI was not significantly different between damaged and undamaged plots in 2000, 2001, or 2005, the most recent year for which we have data on all 32 plots (Fig. 3). Though the 2006 data show an increase in total LAI in damaged areas, we think that this is most likely a result of inter-annual variability. The undamaged plots (the lower elevation band) had an average LAI of $7.0 \mathrm{~m}^{2} / \mathrm{m}^{2} \pm 2.1$; the damaged plots (middle and upper elevation bands) had LAl values of $6.8 \mathrm{~m}^{2} / \mathrm{m}^{2} \pm 0.1$ and 6.1 $\mathrm{m}^{2} / \mathrm{m}^{2} \pm 0.7$ respectively. Together with the data published by Rhoads et al. (2002), these data constitute a time series showing the recovery of total LAI in six of the first nine growing seasons following the 1998 ice storm. Total LAl in the mid and high elevation bands, which were severely damaged by the storm, 
had recovered such that there were no significant differences among elevation bands by 2000 (Rhoads et al. 2002; Fig. 3), and since then the LAI of none of the elevations has changed significantly between growing seasons (paired two-tailed $t$-test; ? ?]=0.05). There is a consistent pattern of a slow increase in LAI at all elevations between 2000 and 2005, though no two years are significantly different for any damage class within this interval. In 2006, the low-elevation plots show significantly lower LAI than in previous years, for which we have no satisfactory explanation (analysis of individual plots over time shows that this is not an effect of fewer plots measured in 2006).

Total LAI currently shows only a weak relationship with elevation in the experimental watersheds (slope $=0.5 \mathrm{LAl}$ units per $100 \mathrm{~m}$ elevation, for a difference of about 1 LAI unit over the elevation range covered by the data; $p$ =0.06; Figure 4a). In contrast, total LAI in 1998, the first growing season post-storm, showed a strong trend with elevation, with each $100 \mathrm{~m}$ increase in elevation resulting in a decrease of 1 $\mathrm{m}^{2} / \mathrm{m}^{2}$ in LAI. ( $\mathrm{p}<0.001$; Fig. 4a). In 1998, elevation explained $37 \%$ of the variance in total LAI, elevation explains only $12 \%$ of the total variance in post-recovery LAI (Fig. 4a). All but one plot increased in total LAI between 1998 and the latest three years of data, though the more severely damaged plots at higher elevation increased far more than the less severely damaged plots at lower elevations (Fig. $4 a)$. Some of the difference in recovery is attributable to forest type. Plots with $<70 \%$ of basal area in beech, birch and maple and thus with larger amounts of red spruce, white birch, and balsam fir, have much lower LAl values post-recovery (2001-2006) than plots with $>70 \%$ northern hardwood basal area, despite there being no significant trend in total LAl with forest composition in the first growing season poststorm (Fig. 4b).

\section{Species composition of canopy strata}

The mean DBH of trees with leaves at each height above $2 \mathrm{~m}$ increases similarly in undamaged and damaged plots, with the only significant difference at $3 \mathrm{~m}$ (unpaired 2-tailed heteroscedastic $t$-test, $\mathrm{n}=89$ branches, $p<$ 0.001; Fig. 5). This result rules out the possibility of branch extension by larger canopy trees being responsible for the increased LAI from 6.0 - $9.9 \mathrm{~m}$ in the damaged plots, and implies an increase in density of smaller trees (10.0 - $14.9 \mathrm{~cm} \mathrm{DBH)} \mathrm{leading} \mathrm{to} \mathrm{the} \mathrm{increase} \mathrm{in}$ LAI from 6.0-9.9m.

The increase in stem density of healthy beech trees between 1997 and 2002 was significantly greater in damaged than undamaged plots in the $5.0-9.9 \mathrm{~cm}$ and $10.0-14.9 \mathrm{~cm}$ DBH classes

(Fig. 6; $p$-values $=<0.001$ and 0.02, respectively; Siccama unpublished data, www.hubbardbrook.org). This latter diameter class is largely responsible for the LAI in the 6.0 - $9.9 \mathrm{~m}$ height class (Fig. 1; Fig. 2). The only other significant difference in stem density over the first five growing seasons post ice storm was for the 20.0 - $29.9 \mathrm{~cm}$ DBH size class which represented the mature trees most heavily damaged by the storm, in this cohort, trees in the damaged plots showed a decrease in healthy beech at a significantly greater rate (Fig. $6 ; p=0.009$ ).

\section{DISCUSSION}

\section{Change in canopy profile of damaged plots}

While total LAI was equal in the damaged and undamaged plots in 2005, the vertical profile of the damaged plots shows that an increased proportion of the total LAI is located between six and ten meters above the ground relative to the undamaged plots. These data indicate that that the mean height of the canopy was lower in plots damaged by the ice storm even eight growing seasons following the storm. This lower canopy can alter the distribution of microhabitats, and has been shown to lead to shifts in the bird community through changes in foraging success and in turn food abundance (Holmes and Sherry 2001). The changes to the vertical profile may also alter the forest's 
photosynthetic and transpiration rates as well as the forest's nutrient content (Aber 1979a; Forester et al. 2000).

One possible mechanism for canopy re-growth following an ice storm is lateral ingrowth by surviving trees in response to increased light. The consistent relationship between branch height and $\mathrm{DBH}$ between damaged and undamaged plots (Fig. 5) suggests that eight years post storm, tree shape does not reflect impacts of ice damage, suggesting that lateral growth was not an important factor in the increase in leaf area from $6-10 \mathrm{~m}$. The observed increase in LAl at lower heights in damaged plots is largely the result of the observed increase in the number of smaller trees, particularly those between 5 and $15 \mathrm{~cm}$ DBH (Fig 6), which correspond with branches in the $6-10 \mathrm{~m}$ height range (Fig 5). This response is due to the release of suppressed beech saplings in canopy openings created by the ice storm. Long-term tree inventory data from W6 shows that beech has been increasing in abundance over the past 40 years, and the ice storm accelerated this transition in areas it impacted. Total biomass of trees $10-16 \mathrm{~cm}$ DBH on W6 declined 34\% between 1965 and 2002, with beech increasing by $43 \%$ and sugar maple decreasing by $66 \%$ in this size class.

While the ice storm damaged beech most heavily (Rhoads et al. 2002), the presence of a large number of beech saplings prior to the storm allowed beech to exceed pre-damage stem counts in intermediate size classes $(<15$ $\mathrm{cm} \mathrm{DBH;} \mathrm{Fig.} \mathrm{6)} \mathrm{and} \mathrm{its} \mathrm{proportional}$ representation in the canopy. The presence of saplings prior to the ice storm was the result of stress from beech bark disease and the response to increase root-suckering (Houston 1975). Disturbances such as the 1998 ice storm, which cause damage to, or death of, larger trees can result in the initiation of large numbers of new beech sprouts, and can also increase growth rates among existing beech saplings (Houston 1975) and seedlings (Cleavitt et al. 2008). Additionally, seedlings of sugar maple, which was recently overtaken by beech as the species with the highest basal area on W6 (Schwarz et al. 2001), competes poorly with beech saplings (Hane 2003; Hane et al. 2003). The survival of sugar maple seedlings on W6 is quite low, though $\mathrm{Ca}$ fertilization on $\mathrm{W} 1$ has recently resulted in improved survivorship (Juice et al. 2006).

Whole-canopy LAI has not increased significantly since the third growing season post-storm (Fig. 3), however the distribution of that foliage remains significantly altered from its pre-damaged state after eight growing seasons (Fig. 1; Fig. 2). We interpret this response as the result of the release of an advance regeneration cohort, which grew into the $5-9 \mathrm{~cm}$ DBH class between the ice storm and 2002 (Fig 6), and which continued to grow and dominate the 6.0-9.9 meter height stratum in 2005 . This sustained shift in canopy composition toward an increased role of intermediate-sized beech could persist longer than successional changes following past instances of disturbance, in part due to the prevalence of beech bark disease and the associated increase in sprouting and outcompeting of previously competitive species like sugar maple. As the dominance of intermediate-sized beech persists, the differences in the vertical structure of the damaged canopy will continue to influence the patterns and processes of the forest and the canopy with the possibility that the vertical foliage-height profile will not return to its previous structure for the foreseeable future. The increased number of beech trees of intermediate size (Fig. 6) as well as the significantly higher number of beech trees with leaves from 2 - $5 \mathrm{~m}$ in the damaged plots suggests that the ice storm opened the canopy and allowed for increased growth and survivorship of beech saplings as well as increased initiation of beech sprouts. This lowering of the canopy may be a relatively novel shift in the structure of the forest. The change in proportion of total LAI in the damaged areas can likely be attributed to impacts of the ice storm damage rather than 
land use history, as there is no significant difference between the proportion of total LAI in the 6.0 - $9.9 \mathrm{~m}$ height class in the undamaged plots of W6 and W1, which are broadly representative of land-use history throughout the White Mountain region, and an undisturbed old-growth forest $30 \mathrm{~km}$ to the east at the Bowl Research Natural Area (Fig. 1; Aber 1979b).

\section{Post-storm recovery of total LAI}

Total LAI was equal to pre-storm values by the third growing season post-storm (2000), and since 2001, there has been no overall trend in total LAI at any elevation, though there may be some coherent pattern of interannual variability (Fig. 3). The areas that were classified as "undamaged" in 1998 also appear to show modest recovery in 2001-2005, though total LAI measured in 2006 was not significantly different from that measured in 1998 and 1999. On average, plots at higher elevations were more heavily damaged than plots at lower elevations, and have recovered more since 1998 (Fig. 3; Fig. 4a). A weakly significant negative trend in total LAI with elevation remains (Fig. 4a), though it is far weaker than the trend predicted by Rhoads et al. (2002) using allometric equations (Whittaker et al. 1974).

Species composition of the understory may dictate the long-term consequences of a major disturbance for canopy structure and species composition. This may explain some of the differences in recovery pattern seen with elevation. Of the five plots with $<70 \%$ of basal area comprised of the dominant northern hardwood species (beech, yellow birch, and sugar maple), four have mean post-recovery total LAI of $<5$, while no plots with $>70 \%$ of basal area in northern hardwoods have postrecovery total LAI values this low (Fig. 4b). Plots with $<70 \%$ of basal area in northern hardwoods tend to be dominated by red spruce, balsam fir, and white birch. This finding is particularly striking in light of the fact that there was no trend in total LAl with species composition in the first growing season post-storm (Fig. 4b). However, we cannot eliminate the alternative hypotheses that some other factor affects both species composition and ability to recover from damage (such as soil depth, or water or nutrient availability), or that these plots had lower LAI before the storm due to other factors. Continued monitoring of these plots will be necessary to determine the pattern of changes over time.

\section{Consequences for forest composition structure and function}

This work supports the conjecture that disturbances such as the ice storm will lead to increased dominance of beech at HBEF. The positive response of beech to increased light is potentially accelerated by beech phytotoxic (Hane et al. 2003) or Ca-depletion (Likens et al. 1998) effects on sugar maple seedlings and saplings. Leak (1987) suggests that sugar maple regeneration on granitic soils is at least somewhat dependent on seedling-layer light availability. Canham (1988) noted that sugar maple had a greater growth response in forest gaps relative to beech, although beech saplings grew more quickly while shade-suppressed (Canham 1990). Somewhat paradoxically, while the beech were found to have been the species that was most damaged by the ice storm, the current age/species structure of the forest implies that the disturbance will ultimately result in a higher importance value for beech, which in turn makes the forest more susceptible to future storm damage. At the HBEF and throughout the northern hardwood forest region, beech bark disease affects nearly all beech trees with a DBH $>20 \mathrm{~cm}$. Because beech bark disease is widespread throughout the region at the elevations where the ice storm caused intense damage, the interaction between these two disturbances is likely widespread. The ice storm appears to have accelerated beech bark disease's negative impacts on forest biomass and economic value (Forrester et al. 2000).

Beech has been shown to benefit relative to sugar maple in cutting experiments where canopy disturbance was moderate (Nolet et al. 
2007), though little effect of cutting on successional shifts in species composition has been observed at Bartlett Experimental Forest, only $50 \mathrm{~km}$ east of HBEF (Leak 1987; Leak and Smith 1996). Beaudet et al. (2007) observed that beech and sugar maple competed equally well in gaps created by the 1998 ice storm in Quebec, Takahashi et al. (2007) saw no substantial change in overall species composition attributable to the ice storm, also in southern Quebec. Increased beech dominance at HBEF in response to the ice storm appears to be idiosyncratic, and may relate in part to the poor regeneration of sugar maple. The extent to which other sites in the northern hardwood region exhibit this response is variable, and likely depends on a wide range of factors including edaphic factors and land-use history.

Heavy root-sprouting does not appear to be a universal response to beech bark disease. At Bartlett Experimental Forest, beech dominance has changed little over the past 60 years, either in the canopy (Leak and Smith 1996) or understory (Leak 2006). However, a major effect of the disease on sprouting is observed at HBEF (Hane 2003). Houston (2001) observed that disease-resistant beech support more numerous and healthier root sprouts than their disease-susceptible neighbors. To the extent that resistant trees are sufficiently numerous, this effect would be expected to reduce the incidence of beech bark disease (and therefore reduce both ice damage and stress-induced root sprouting) in future generations of beech. In the absence of increasing resistance, we would expect beech root-sprout dominance of the advance regeneration cohort to continue, with more frequent release of dense subcanopy layers under in a generally shorter, more damage-prone canopy.

The increase in the dominance of beech, which has low foliar concentrations of base cations and $\mathrm{N}$ relative to other dominant hardwoods at HBEF (Likens and Bormann 1970), can also be expected to affect biogeochemical cycles (Finzi et al. 1998a,b). A shift towards a more beech- dominated forest may also lead to lower total aboveground biomass as a result of premature death due to beech bark disease, though annual litterfall can be expected to remain constant (Forester et al. 2000). While such changes are not likely to be reflected in measurements of total LAI, they might have an effect on foliageheight profiles, with canopy height being reduced on a sustained basis.

The ice storm of 1998 is only one of many natural and anthropogenic disturbances to the HBEF ecosystem and others like it throughout northern New England, including hurricanes, historical harvesting (Goodale and Aber 2001), climate change, $\mathrm{N}$ deposition and acidification (Likens et al. 1998), and disease. The interaction of these factors will determine the structure, composition, and function of these ecosystems in the decades and centuries to come. The data presented here provide a baseline for future studies of changing canopy profiles in one of the most intensively studied forests in the world.

\section{CONCLUSIONS}

We set out four hypotheses related to the effects of the 1998 ice storm on the importance of beech at the Hubbard Brook Experimental Forest to address the conjecture that the ice storm in conjunction with beech bark disease may increase the importance of beech in the forest, at least temporarily. Our data suggest that this is in fact the case, as the data support each of the sub-hypotheses.

Canopy-height profiles of forest stands damaged in the 1998 ice storm are significantly different than undamaged areas eight years post-storm, even while the total LAI of areas damaged in 1998 has recovered to pre-storm levels and has been stable since 2000 (hypothesis 1). The relative importance of beech leaf area has increased more than that of other tree species in damaged areas (hypothesis 2). In areas damaged by the 1998 ice storm, but without advance beech regeneration, LAI has been slower to recover 
than in areas with abundant beech regeneration (hypothesis 3 ). The density of intermediate-sized beech trees $(5.0-14.9 \mathrm{~cm}$ $\mathrm{DBH}$ ) has increased more in damaged areas than undamaged areas (hypothesis 4).

\section{ACKNOWLEDGEMENTS}

Previously unpublished LAI data presented here were collected with the assistance of Anne Rhoads, Tess Belmont, Molly Deringer, Stephan Wollenburg, Becca Berwick, and Zach Feeser. We thank Dick Holmes for the use of his modified 35-mm camera in measuring canopy height-profiles. Vegetation data were taken under supervision of T.G. Siccama and are available at www.hubbardbrook.org. The Hubbard Brook Experimental Forest is operated by the Northern Research Station, US Department of Agriculture, Newtown Square, PA, and is part of the NSF-funded Long-term Ecological Research network (Iternet.edu). This work was funded by National Science Foundation grant 0423259 , and is a contribution to the Hubbard Brook Ecosystem Study (www.hubbardbrook.org).

\section{REFERENCES}

Aber, J.D. 1979a. A Method for Estimating Foliage-Height Profiles in Broad-Leaved Forests. The Journal of Ecology 67: 35-40.

Aber, J.D. 1979b. Foliage-height profiles and succession in northern hardwood forests. Ecology 60: 18-23.

Bailey, A S., J.W. Hornbeck, J.L. Campbell, C. Eager. 2003. Hydrometeorological Database for Hubbard Brook Experimental Forest: 19552000. USDA Forest Service General Technical Report NE-305.

Battles, J.J., and T.J. Fahey. 2000. Gap dynamics following forest decline: a case study of red spruce forests. Ecologial Applications 10: 760774.
Boerner, R.J., S.D. Runge, D. Cho, and J.G. Kooser. 1988. Localized ice storm damage in an Appalachian Plateau watershed. American Midland Naturalist 119: 199-208.

Bofinger, J. 2001. New Hampshire ice storm damage assessment and response. In New York Society of American Foresters Ice Storm Symposium. USDA Forest Service, Cortland, N.Y. Publ. NA-TP-03-01.

Bormann, F.H., T.G. Siccama, G.E. Likens, and R.H. Whittaker. 1970. The Hubbard Brook Ecosystem: composition and dynamics of the tree stratum. Ecological Monographs 40: 373-388.

Canham, C.D. 1988. Growth and architecture of shade-tolerant trees: Response to canopy gaps. Ecology 69: 786-795.

Canham, C.D. 1990. Suppression and Release during canopy recruitment in Fagus grandifolia. Bulletin of the Torrey Botanical Club 117: 1-7.

Cleavitt, N.L., M. Fairbairn, and T.J. Fahey. 2008. Growth and survivorship of American beech (Fagus grandifolia Ehrh.) seedlings in a northern hardwood forest following a mast event. Journal of the Torrey Botanical Society 135: 328-345.

Coops, N.C., M.L. Smith, K.L. Jacobsen, M. Martin, and S. Ollinger. 2004. Estimation of plant and leaf area index using three techniques in a mature native eucalypt canopy. Austral Ecology 29: 332-341.

DeGaetano, A.T. 2000. Climatic perspective and impacts of the 1998 northern New York and New England ice storm. Bulletin of the American Meteorological Society. 81: 237254.

Digregorio, L.M., M.E. Kasny, and T.J. Fahey. 1999. Radial growth trends of sugar maple (Acer Saccharum) in an Allegheny northern hardwood forest affected by beech bark disease. Journal of the Torrey Botanical Society 126: 245-254. 
Dobbs, D. 1999. The 1998 Ice Storm: Disaster of Disturbance? Northern Woodland. 23: 33-36.

Faccio, S.D. 2003. Effects of ice storm-created gaps on forest breeding bird communities in central Vermont. Forest Ecology and Management 186: 133-145.

Fahey, T.J., T.G. Siccama, C.T. Driscoll, G.E. Likens, J. Campbell, C.E. Johnson, J.D. Aber, J.J. Cole, M.C. Fisk, P.M. Groffman, R.T. Holmes, P.A. Schwarz and R.D. Yanai. 2005. The biogeochemistry of carbon at Hubbard Brook. Biogeochemistry 75: 109-176.

Finzi, A.C., N. Van Breemen, and C.D. Canham. 1998a. Canopy tree-soil interactions within temperate forests: species effects on soil carbon and nitrogen. Ecological Applications 8: 440-446.

Finzi, A.C., N. Van Breemen, and C.D. Canham. 1998b. Canopy tree-soil interactions within temperate forests: species effects on $\mathrm{pH}$ and cations. Ecological Applications 8: 447-454.

Forester, J.A., G.G. McGee, and M.J. Mitchell. 2003. Effects of beech bark disease on aboveground biomass and species composition in a mature northern hardwood forest. Journal of the Torrey Botanical Society 130: 70-78.

Goodale, C.L., and J.D. Aber. 2001. The longterm effects of land-use history on nitrogen cycling in northern hardwood forests. Ecological Applications 11: 253-267.

Hane, E.N. 2003. Indirect effects of beech bark disease on sugar maple seedling survival. Canandian Journal of Forest Research 33: 807813.

Hane, E.N., S.P. Hamburg, A.L. Barber, J.A. Plaut. 2003. Phytotoxicity of American beech leaf leachate to sugar maple seedlings in a greenhouse experiment. Canadian Journal of Forest Research 33: 814-821.

Holmes, R.T., and T.W. Sherry. 2001. Thirtyyear bird population trends in an unfragmented temperate deciduous forest:
Importance of habitat change. The Auk 118: 589-609.

Hooper, M.C., K. Arii, and M.J. Lechowicz. Impact of a major ice storm on an old-growth hardwood forest. Canadian Journal of Botany 79: 70-75.

Houston, D.R. 2001. Effect of harvesting regime on beech root sprouts and seedlings in a north-central Maine forest long affected by beech bark disease. USDA Forest Service Research Paper NE-717.

Irland, L.C. 1998. Ice storm 1998 and the forests of the northeast. Journal of Forestry 96(9): $32-40$.

Juice, S. M., T. J. Fahey, T. G. Siccama, C. T. Driscoll, E. G. Denny, C. Eagar, N. L. Cleavitt, R. Minocha and A. D. Richardson. 2006. Response of sugar maple to calcium addition to northern hardwood forest. Ecology 87: 1267-1280.

Leak, W.B. 1987. Fifty years of compositional change in deciduous and coniferous forest types in New Hampshire. Canadian Journal of Forest Research 17: 388-393.

Leak, W.B. 2006. Sixty years of change in the sapling understories of northern hardwood selection stands in New Hampshire. Northern Journal of Applied Forestry 23: 301-303.

Leak, W.B., and M.L. Smith. 1996. Sixty years of management and natural disturbance in a New England forested landscape. Forest Ecology and Management 81: 63-73.

Lemon, P.C. 1961. Forest Ecology of Ice Storms. Bulletin of the Torrey Botanical Club 88: 21-29.

Likens G.E., and F.H. Bormann. 1970. Chemical analyses of plant tissues from the Hubbard Brook Ecosystem in New Hampshire. Yale University: School of Forestry. Bulletin 79.

Likens G.E., C.T. Driscoll, D.C. Buso, T.G. Siccama, C.E. Johnson, G.M. Lovett, T.J. Fahey, W.A. Reiners, D.F. Ryan, C.W. Martin, and S.W. Bailey. 1998. The biogeochemistry of 
calcium at Hubbard Brook. Biogeochemistry 41: 89-173.

Lovett, G. M., and H. Rueth. 1999. Soil nitrogen transformations in beech and maple stands along a nitrogen deposition gradient. Ecological Applications 9: 1330-1344.

Macarthur, R.H., and H.S. Horn. 1969. Foliage profile by vertical measurement. Ecology 50: 802-804.

MacArthur, R.H., and J.W. MacArthur. 1961. On Species Diversity. Ecology 42: 594-598.

Melancon, S, and M.J. Lechowicz. 1987. Differences in the damage caused by glaze ice on codominant Acer saccharum and Fagus grandifolia. Canadian Journal of Botany 65: 1157-1159.

Mou, P., and M.P. Warrilow. 2000. Ice storm damage to a mixed hardwood forest and its impacts on forest regeneration in the ridge and valley region of southwestern Virginia. Journal of Torrey Botanical Society 127: 6682.

Oliver, C D., and B C. Larson. 1996. Forest Stand Dynamics. John Wiley and Sons, Inc. New York.

Peters, S.C., J.D. Bloom, C.T. Driscoll, and G.E. Likens. 2004. Dissolution of wollastonite during the experimental manipulation of Hubbard Brook Watershed 1. Biogeochemistry 67: 309-329.

Rhoads, A.G., S.P. Hamburg, T.J. Fahey, T. G. Siccama, E. N. Hane, J. Battles, C. Cogbill, J. Randall, and G. Wilson. 2002. Effects of an intense ice storm on the structure of a northern hardwood forest. Canadian Journal of Forest Research 32: 1763-1775.

Rhoads, A.G., S.P. Hamburg, T.J. Fahey, T.G. Siccama, and R. Kobe. 2004. Comparing direct and indirect methods of assessing canopy structure in a northern hardwood forest. Canadian Journal of Forest Research 34: 584-591.
Robinson, S.K., and R.T. Holmes. 1982. Foraging Behavior of Forest Birds: the relationships among search tactics, diet, and habitat structure. Ecology 63: 1918-1931.

Schwarz, P.A., T.J. Fahey, C.W. Martin, T.G. Siccama, and A. Bailey. 2001. Structure and composition of three northern hardwoodconifer forests with differing disturbance histories. Forest Ecology and Management 144: 201-212.

Seischab, F K., J M. Bernard, and M D. Eberle. 1993. Glaze storm damage to western New York forest communities. Bulletein of the Torrey Botanical Club 120: 64-72.

Takahashi, K., K. Arii, and M.J. Lechowicz. 2007. Quantitative and qualitative effects of a severe ice storm on an old-growth beechmaple forest. Canadian Journal of Forest Research 37: 598-606.

Warrilow, M., and P. Mou. 1999. Ice storm damage to forest tree species in the ridge and valley region of southwestern Virginia. Journal of the Torrey Botanical Society 126: 147-158

Whitney, H.E., and Johnson, W.C. 1984. Ice storms and forest succession in southwestern Virginia. Bull. Torrey Bot. Club, 111: 429-437.

Whittaker, R H., F H. Bormann, G E. Likens, and T G. Siccama. 1974. The Hubbard Brook Ecosystem Study: forest biomass and production. Ecological Monographs 44: 233252. 
Figure 1. Percentage of total canopy leaf area index within four canopy strata in damaged $(n=7)$ and undamaged $(n=4)$ plots on W6 of the Hubbard Brook Experimental Forest eight years following the 1998 ice storm. Error bars show 95\% confidence intervals. For reference, data from a 200+ year-old stand at The Bowl Research Natural Area from Aber (1979) is included. These data were collected using the camera method.

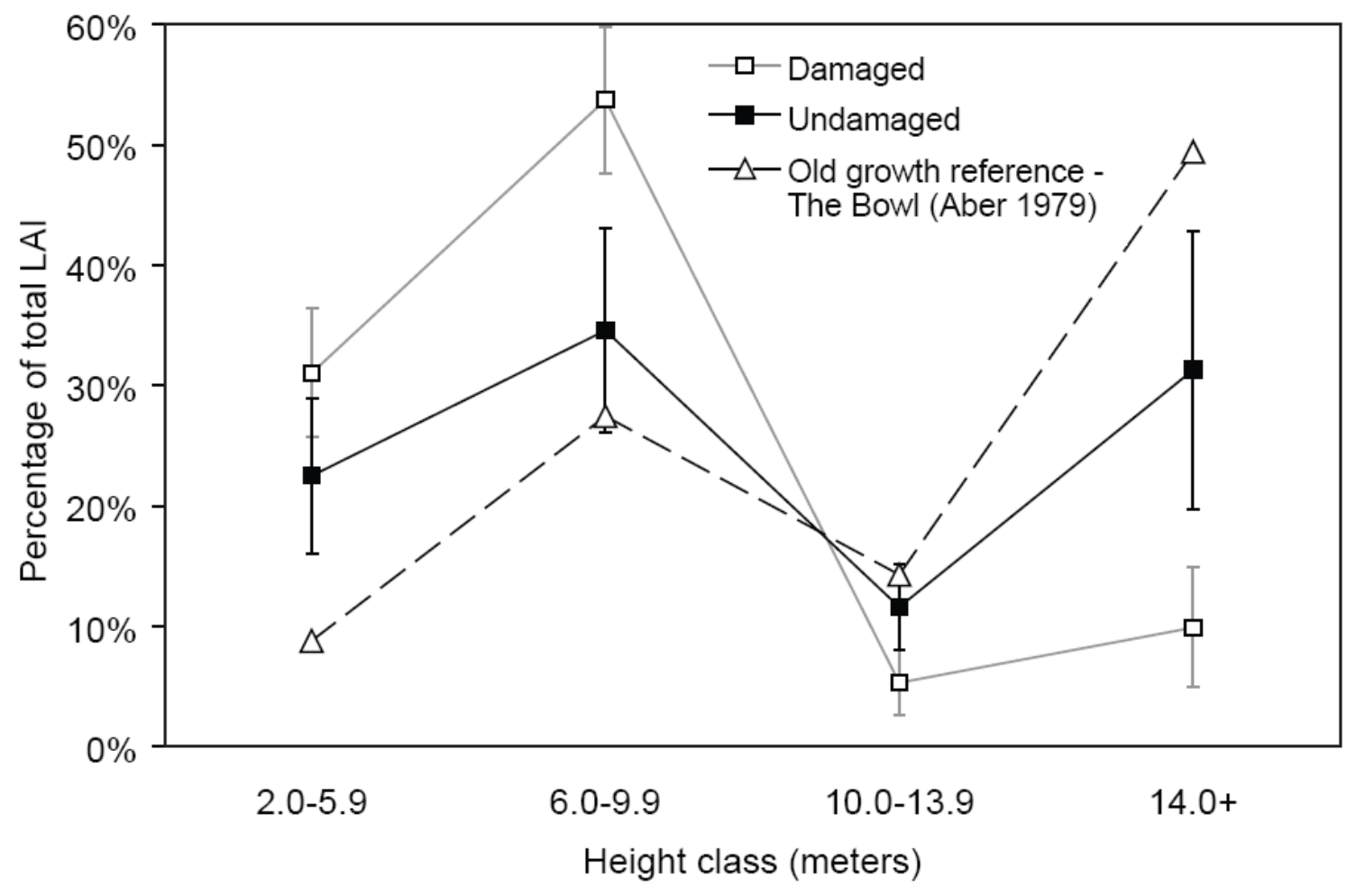


Figure 2. Leaf area index height profiles for damaged and undamaged plots in W6 of the Hubbard Brook Experimental Forest eight years following the 1998 ice storm. Data were collected using the elevated LAI-2000 method. Error bars show_95\% confidence intervals.

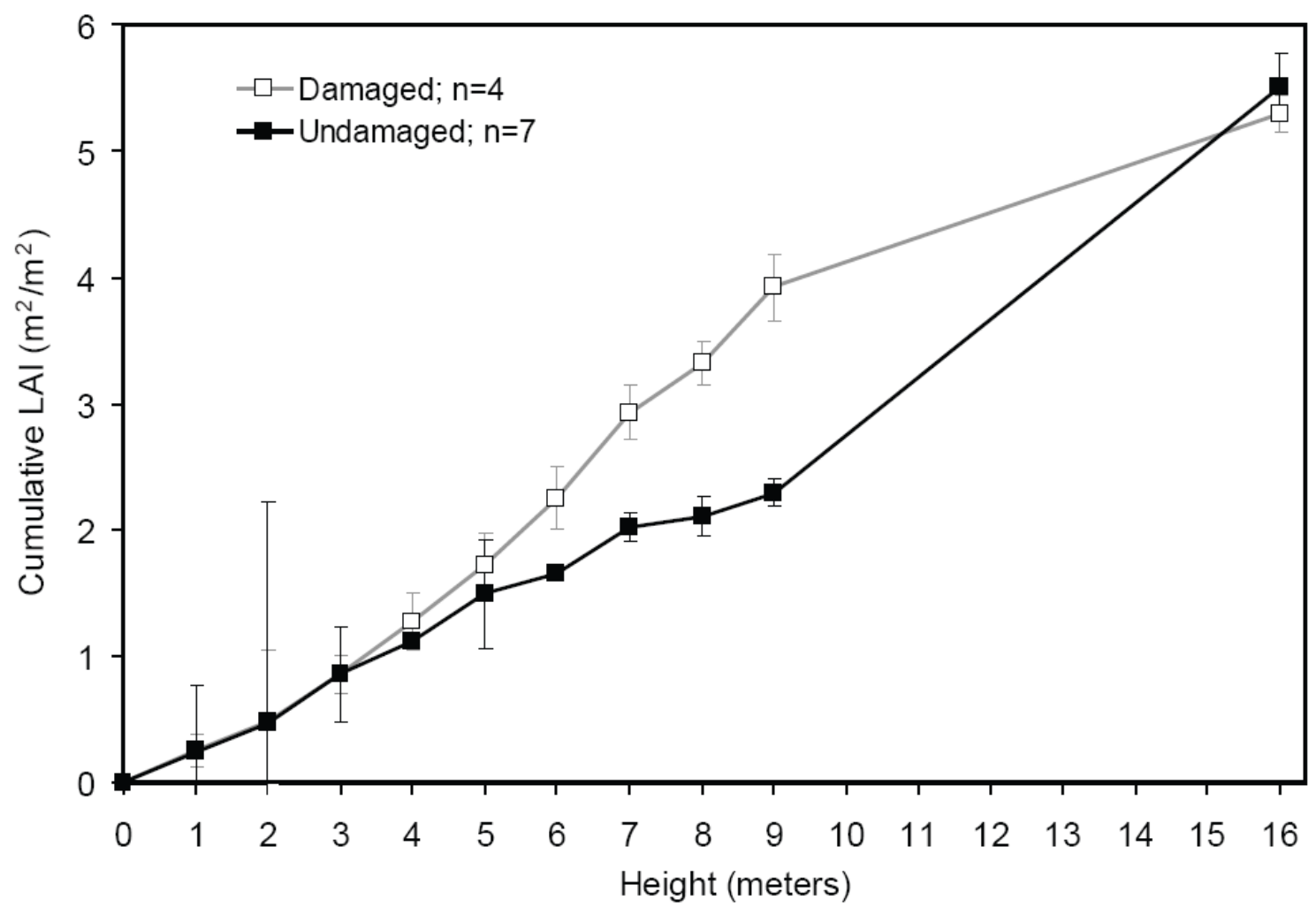


Figure 3. Mean leaf area index by elevation, and damage class, in growing seasons 1-4 and 8-9 after the 1998 ice storm within watersheds 1 and 6 of the Hubbard Brook Experimental Forest in Woodstock, NH. Error bars show 95\% confidence intervals for means. Data for 1998-2000 were previously reported by Rhoads et al. (2002).

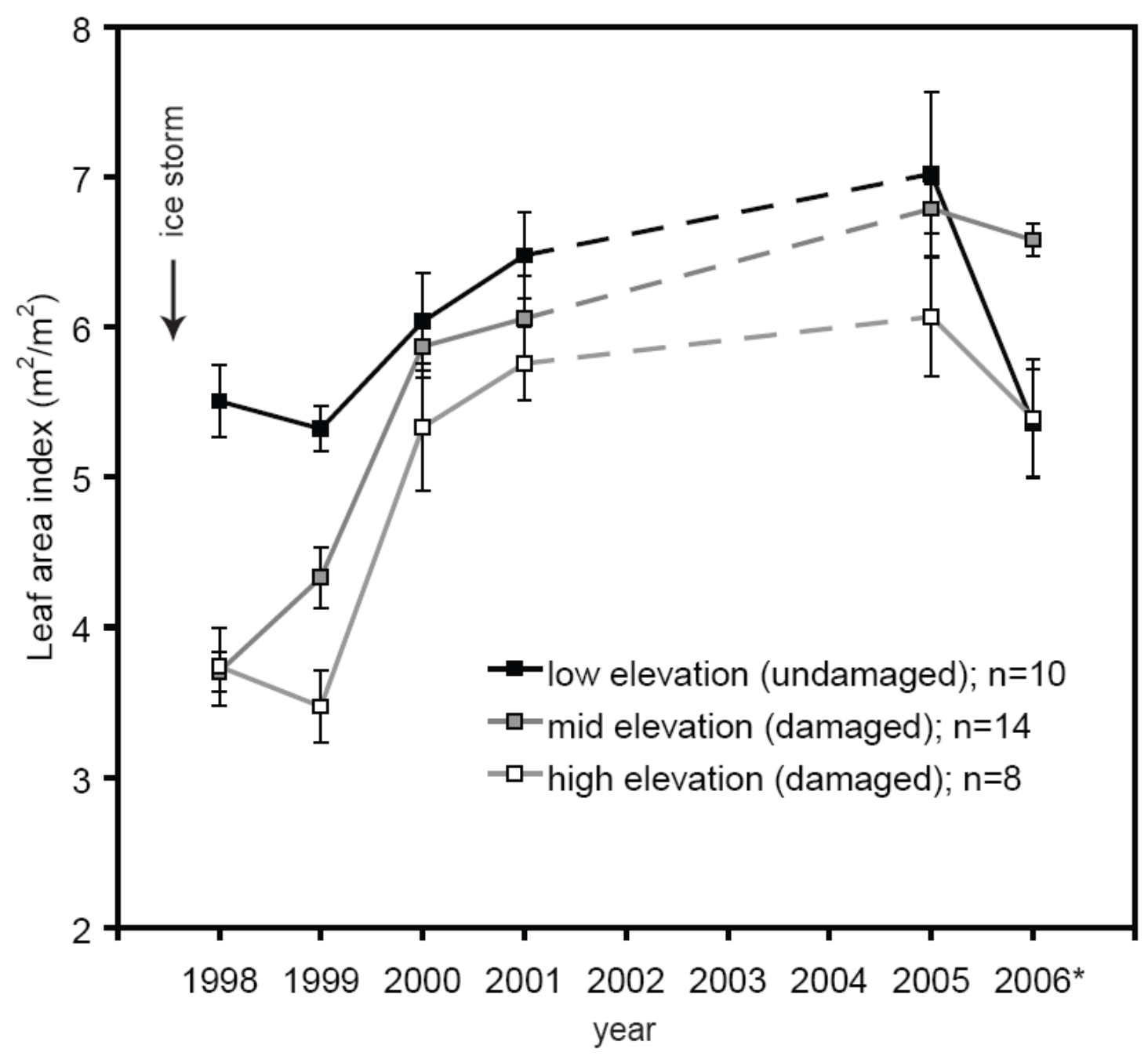

* Data for 2006 are from W6 only (total $n=17)$. 
Figure 4. Plot-level leaf area index values from the first growing season following the 1998 ice storm at the Hubbard Brook Experimental Forest and the mean of three postrecovery years (2001, 2005, and 2006), plotted against (a) elevation, and (b) percentage of each plot's basal area in beech, birch and maple.
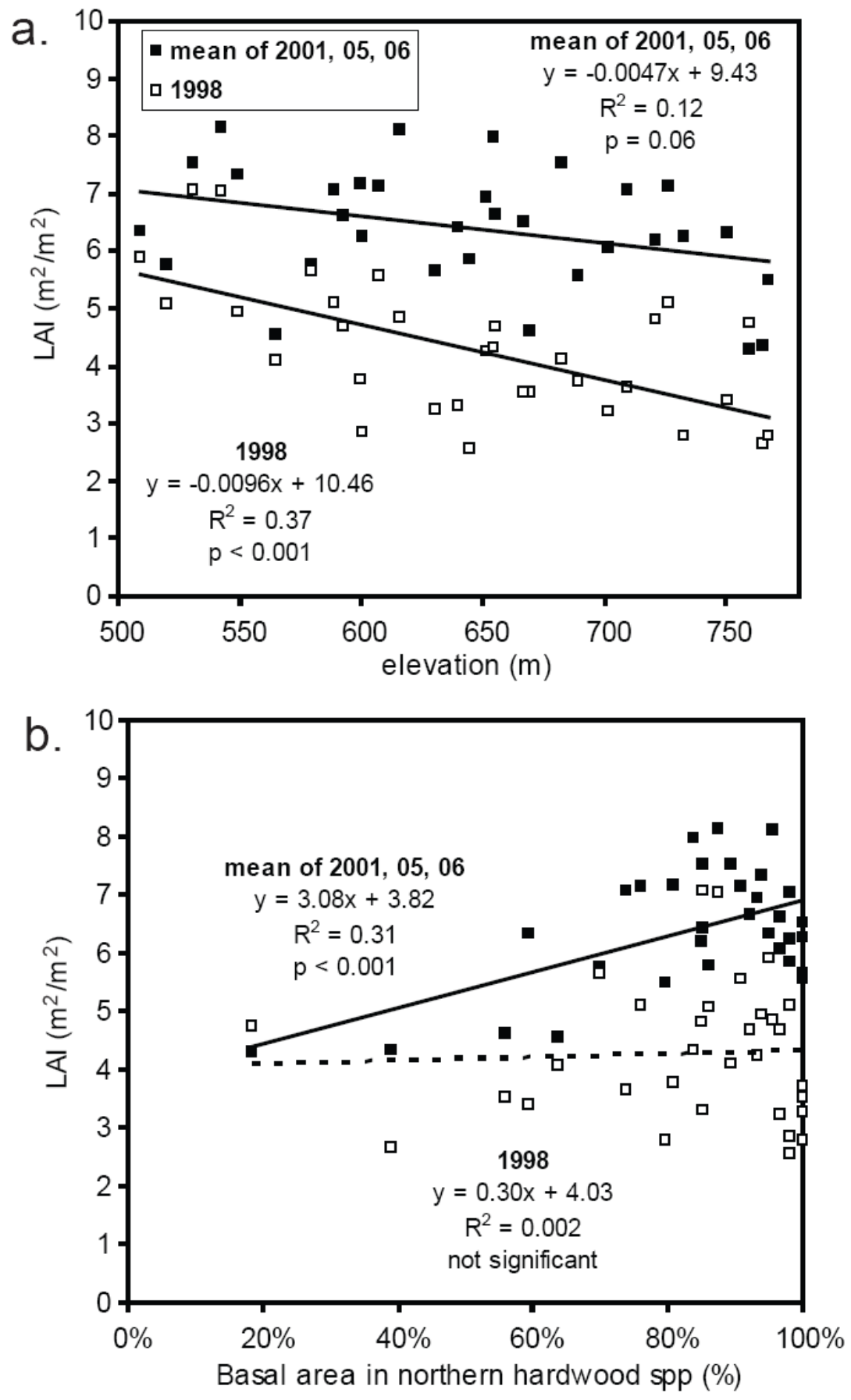
Figure 5. The mean diameter at breast height of trees with branches at each canopy height in W6 of the Hubbard Brook Experimental Forest. Error bars show 95\% confidence intervals for means.

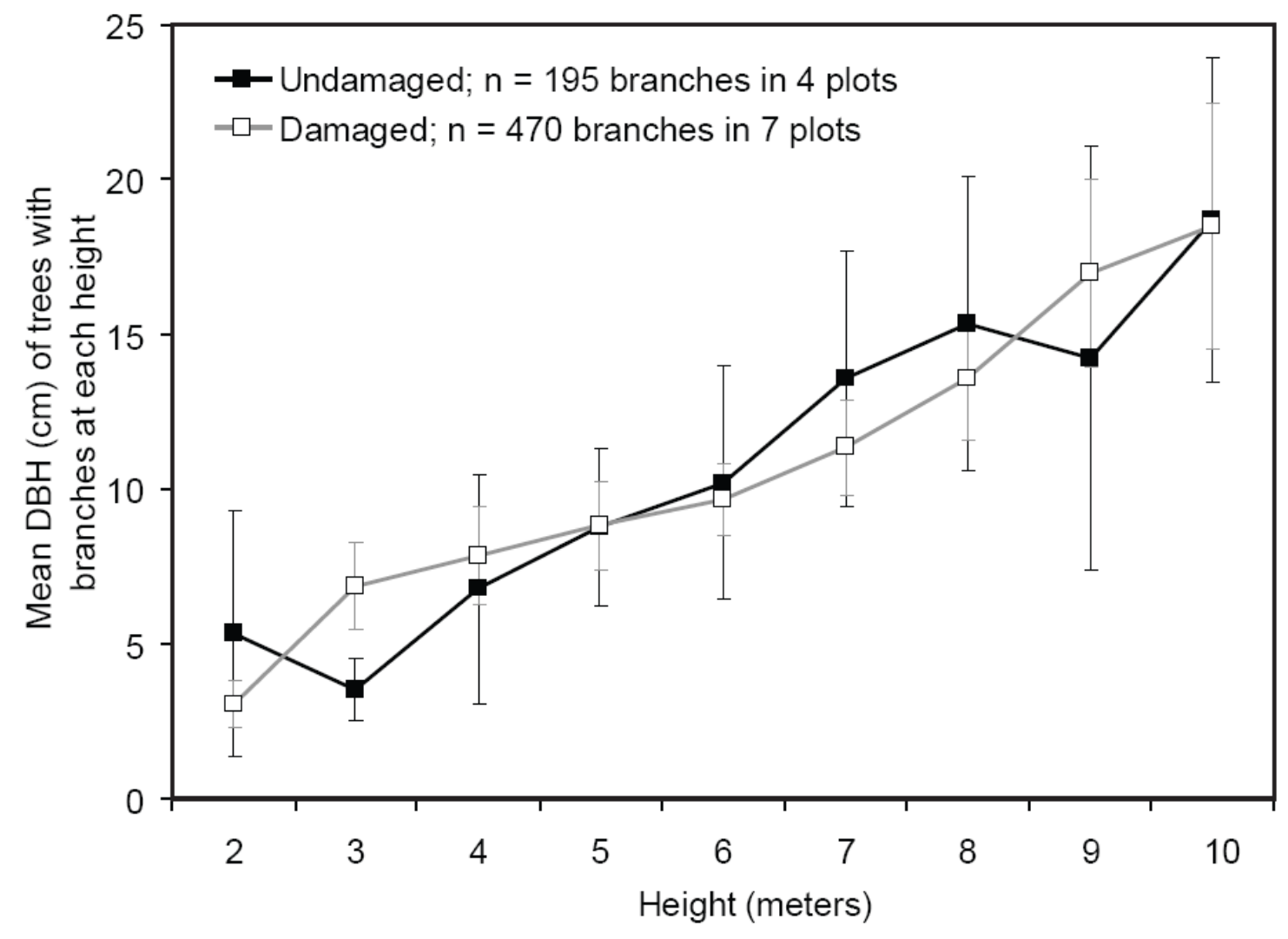


Figure 6. Changes in stem density of healthy beech trees between 1997, prior to the ice storm and 2002, after the ice storm, in ice storm damaged and undamaged areas of W6. Asterisks show the size classes for which the absolute changes are significantly different between damaged and undamaged areas. ${ }^{* * *}=p<0.001 ;{ }^{* *}=p<0.01 ;^{*}=p<0.05$. The numbers in each bar show the absolute change in stem density per hectare.

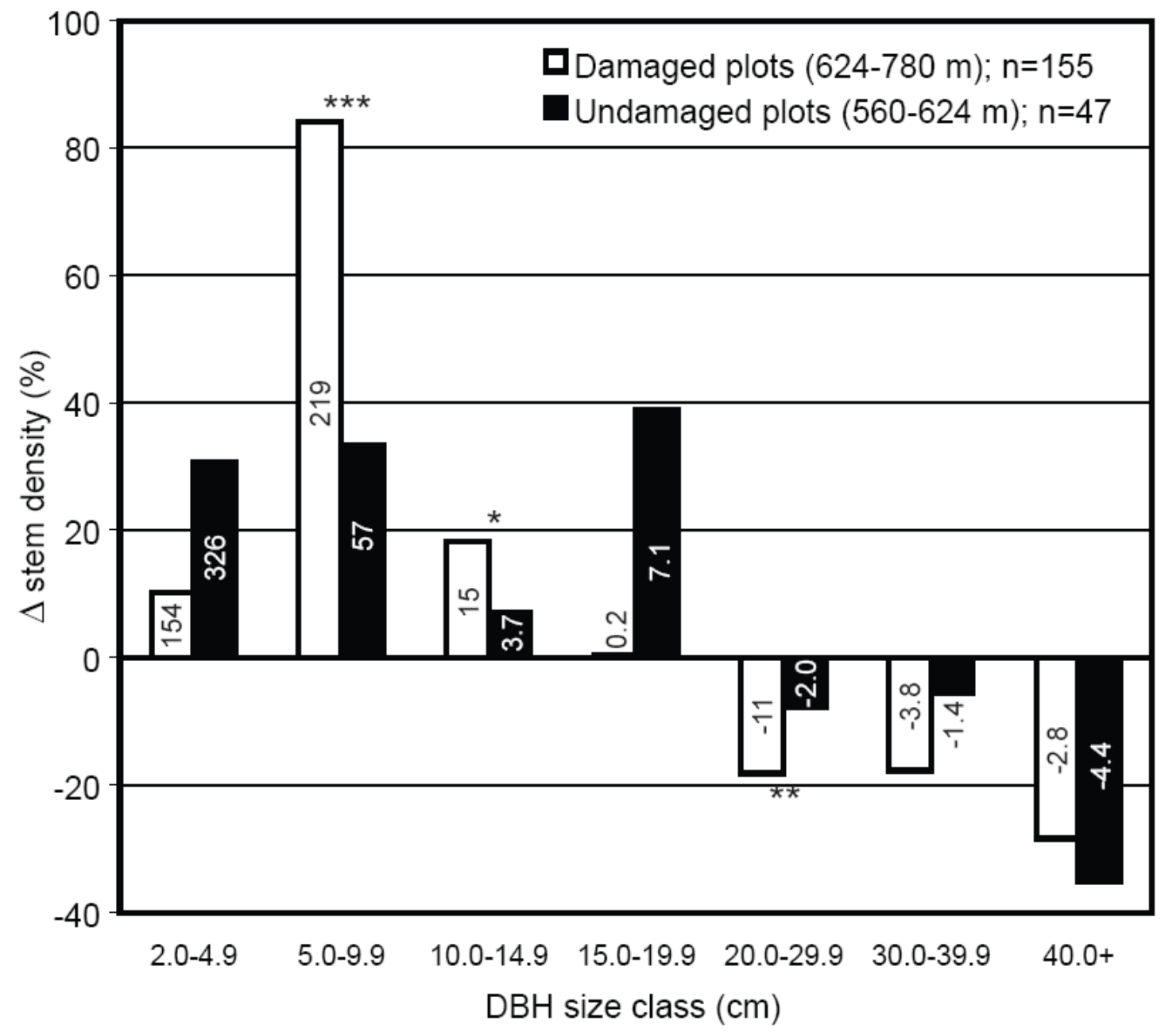

